\title{
NUMERICAL ANALYSIS OF EFFECTS OF HYDRAULIC GRADIENT ON MASS FLUX OF SALTWATER INTRUSION IN COASTAL AQUIFERS
}

\author{
JAMES A. ADEGOKE ${ }^{1}$, OLATUNDE I. POPOOLA ${ }^{1}$, OLUDOTUN O. FALUY ${ }^{1,2^{*}}$ \\ ${ }^{I}$ Department of Physics, University of Ibadan, Ibadan, Nigeria \\ ${ }^{2}$ Department of Physics and Materials Science, Kwara State University, \\ Malete Kwara State, Nigeria
}

\begin{abstract}
Coastal aquifers are distinguished from other aquifers because of saltwater intrusion effects, which cause contamination of groundwater in coastal regions. This study addressed the significance of hydraulic gradient and porosity of the coastal aquifers on contaminant transport of saltwater. Results showed hydraulic gradient of the aquifer has significant impact on the contaminant transport in coastal aquifer. When the hydraulic gradient between freshwater and saltwater is high and directed toward the sea, diffused rate of saltwater into the groundwater would be low. Therefore, hydraulic head of freshwater in coastal aquifer must be maintained at high level to control saltwater intrusion.
\end{abstract}

Keywords: mass flux, hydraulic gradient, coastal aquifer, freshwater and saltwater intrusion

\section{INTRODUCTION}

Groundwater is a major source of freshwater accounting for almost $99 \%$ of the total volume of circulating freshwater today [1]. Bearing in mind the world's Population living along the coasts, coastal aquifers are very important sources of freshwater that must be sustained. These aquifers are connected to the sea and interface exists between fresh and saline water body. In many areas around the world this saline interface has moved landward causing saline intrusion when groundwater abstraction has exceeded recharge [2]. Understanding of the recharge, movement and interaction of groundwater are essential to provide adequate management of water resources. This study provides a discussion of groundwater movement, saline interfaces and groundwater interactions. It focuses specifically on unconfined aquifers, and provides a basis for the methodologies used in this study.

Population growth and agricultural development in coastal areas has increased the demand for freshwater. As a result of this demand more stress is being placed on coastal aquifers. Saltwater intrusion is unarguably the most common contamination problem in aquifers, and a major constraint imposed on groundwater utilization [3]. When pumping takes place in excess of replenishment, the drawdown of the water table creates a piezometric head in the fresh water that becomes less than in the adjacent salt water wedge. Then the saline water moves inland causing a saltwater intrusion. A natural equilibrium exists between discharging fresh groundwater and seawater in coastal aquifers. This is referred to as the saline interface in this study, but it is also known as the sea/saltwater-freshwater interface. The position of the saline interface is dynamic and depends on the geological formation, hydraulic gradient, topography, and the quantity of freshwater moving through the aquifer system. A reduction in groundwater recharge, or an increase in abstraction, can reduce the hydraulic gradient, the

\footnotetext{
*Corresponding author, email: oludotunfaluyi@gmail.com

(c) 2016 Alma Mater Publishing House
} 
freshwater hydrostatic pressure, and the movement of freshwater. This can cause the saline interface to move landwards resulting in saline intrusion and a reduction in water quality. As seawater has a chloride concentration of approximately $19 \mathrm{~g} / \mathrm{L}$, very little seawater is required to contaminate freshwater [4]. Therefore, proactive management of coastal aquifers is essential to ensure sustainable water resource development.

When the difference in the hydraulic heads of saltwater and freshwater is high; the hydraulic gradient of groundwater in coastal region will be high. Therefore, the saltwater (seawater) will flow towards the inland if the fresh groundwater is over abstracted [5]. Seawater intrusion can be prevented by maintenance of groundwater levels well above the sea level. This can be accomplished by reducing groundwater extractions modifying the patterns [6].

Groundwater flow systems define water movement from zones of recharge to zones of discharge. The geology and topography of an area are the major controls on how groundwater will flow, and where the recharge and discharge zones of the system are located. Geological parameters such as structure and aquifer heterogeneity can affect areas of recharge and discharge. They also control the hydraulic characteristics of a groundwater system [7]. Groundwater will flow from recharge areas to discharge areas along preferential flow paths that have the highest permeability. The zone of high permeability within the groundwater media will act as drains. This will increase the vertical gradient in the overlying media, and reduce the horizontal gradient resulting in an increased rate of groundwater flow [7, 8]. Topography determines hydraulic gradient and so affects the groundwater flow direction and discharge rate.

Under normal conditions fresh water flows from inland aquifers and recharge areas to coastal discharge areas to the sea. In general, groundwater flows from areas with higher groundwater levels (hydraulic head) to areas with lower groundwater levels. This natural movement of fresh water towards the sea prevents salt water from entering freshwater coastal aquifers [9].

In coastal aquifers under natural conditions, the lower density freshwater lies over the higher density saline water and the flow is usually from the aquifer to the sea and the discharge zone to the sea is immediately above interface of saltwater and freshwater. Mixing of freshwater and saltwater occurs only by molecular diffusion while mechanical dispersion and advection are negligible because the aquifer is assumed homogeneous which results in steady state flow of seepage velocity [10]. As a result, the mixing zone between saltwater and freshwater is small compared to the thickness of the aquifer, and an abrupt, well-defined interface is usually assumed. At a point on the interface between the fresh and saline waters, the pressure of the freshwater, $\rho_{f} \cdot g \cdot h_{f}$, usually exceeds the pressure of the saline water, $\rho_{s} \cdot g \cdot h_{s}$, causing the flow from land to sea. The fresh and saline ground waters have densities $\rho_{f}$ and $\rho_{s}$. But when pumping takes place in excess of replenishment, the drawdown of the water table creates a piezometric head in the freshwater that becomes less than in the adjacent salt water wedge. Then the saline water moves inland causing a saltwater intrusion.

In homogeneous coastal aquifer, the groundwater flow and seepage velocity is steady, therefore, transport mechanisms due to advection and dispersion are negligible because they occur at bulk flow and variable velocity respectively. It is diffusion alone that occurs in homogeneous aquifer. When groundwater flow velocity is large enough, molecular diffusion is negligible [11]. The effect of molecular diffusion increases as flow velocities decrease. Thus molecular diffusion may be the governing transport mechanism in un-fractured clays with low hydraulic conductivities. Molecular diffusion can generally be neglected in sand aquifers with high flow velocities. In this study, we consider the case of two adjacent saturated strata. The first is initially with zero concentration throughout its length $C(\mathrm{x}, 0)=0$, and the second stratum maintains constant concentration at the interface $C(0, \mathrm{t})=C_{0}$. Because of the constant concentration at the interface, diffusion takes place from the interface into the first stratum. Far away in the first stratum, where the effect of diffusion has not been yet reached, the concentration is still zero, namely $C(\infty, \mathrm{t})=0$ i.e.

Initial condition is $C(\mathrm{x}, \mathrm{t})=0$, when $x \neq 0$ and $t=0$.

Boundary conditions, $C(0, \mathrm{t})=C_{0}$, when $\mathrm{x}=0$ and $t \geq 0$ at the interface. 
Also, $C(\mathrm{x}, \mathrm{t})=0$, with $x=\infty$ and $t \geq 0$.

This study presents the effect of hydraulic gradient of fresh groundwater on the mass flux of saltwater into the freshwater aquifers and establishes the relationship between the seepage velocity of fresh groundwater and mass flux of saltwater.

\section{THEORETICAL BACKGROUND}

Subsurface water flow is governed by Darcy's law and the transport of contaminant in coastal aquifers such as saltwater intrusion is based on Fick's laws of diffusion. The properties of the coastal aquifers such as hydraulic conductivity, effective porosity and hydraulic gradient affect saltwater intrusion into fresh groundwater aquifer. These properties of aquifer contribute to the ability of the aquifer to reduce the severity of groundwater contamination which is known as soil attenuation or soil filtration.

The mass flux of saltwater intrusion in coastal aquifer can be modeled by combining Darcy's law and Fick's laws. According to Darcy's law, the volumetric flow rate per unit area (volume flux) is directly proportional to the hydraulic gradient $[1,12]$ :

$$
q=-k \cdot \frac{\rho}{\mu} \cdot g \cdot \frac{d h}{d l}
$$

Where:

$\mathrm{k}$ is the intrinsic permeability of the porous media;

$\mu$-dynamic viscosity of the fluid;

$\rho$ - density of the fluid;

$\mathrm{g}$ - acceleration due to gravity;

$\frac{d h}{d l}$ - the hydraulic gradient.

The term $k \cdot \frac{\rho}{\mu} \cdot g$ in equation (1) is hydraulic conductivity, which is denoted by $\mathrm{K}$.

Seepage velocity $(\mathrm{V})$ is the volume flux per porosity of the medium i.e.:

$$
V=\frac{q}{\varnothing}
$$

According to first Fick's law of diffusion, the amount of mass of saltwater passing through a unit area per unit time is called mass flux in $\mathrm{kgm}^{-2} \mathrm{~s}^{-1}$. The mass flux is directly proportional to the gradient of concentration [13].

$$
J=-D^{*} \cdot \frac{d c}{d x}
$$

Where:

$\mathbf{J}$ is mass flux of substance $\left(\mathrm{Kg} / \mathrm{m}^{2} \mathrm{~s}\right)$;

$D^{*}$ - coefficient of diffusion;

$\frac{d c}{d x}$ - gradient of concentration.

According to one-dimensional second Fick's law of diffusion, the rate of change of concentration with time is directly proportional to the square of concentration gradient i.e.: 
and

$$
\frac{d c(\mathrm{x}, \mathrm{t})}{d t} \infty \frac{d^{2} \cdot c(\mathrm{x}, \mathrm{t})}{d x^{2}}
$$

$$
\frac{d c(\mathrm{x}, \mathrm{t})}{d t}=D^{*} \frac{d^{2} \cdot c(\mathrm{x}, \mathrm{t})}{d x^{2}}
$$

Where:

$\mathrm{c}$ is the concentration of saltwater in porous medium;

$\mathrm{t}$ - the time of diffusion and $\mathrm{x}$ is the distance (length) of diffusion.

Multiply both sides of equation (3) by dt, the mass flux is obtained and expressed as:

$$
J=-\frac{D}{V} \cdot \frac{d c}{d x}
$$

The concentration of saltwater as exponential function of time t can be express as [14] and [15].

$$
C=C_{0} \exp \left(-\lambda_{t} \mathrm{t}\right)
$$

The concentration of saltwater as exponential function of distance $\mathrm{x}$ can be express as [15].

$$
C=C_{0} \exp \left(-\lambda_{x} \mathrm{x}\right)
$$

Where $\lambda_{t}$ is the coefficient of attenuation and $\lambda_{x}$.

Differentiate equation (6) with respect to time t:

$$
\frac{d c}{d t}=-\lambda_{t} \cdot C_{0} \exp \left(-\lambda_{t} \cdot \mathrm{t}\right)
$$

Differentiate equation (7) with respect to distance $\mathrm{x}$ twice:

$$
\frac{d^{2} c}{d x^{2}}=\lambda_{x}^{2} \cdot C_{0} \exp \left(-\lambda_{x} \cdot \mathrm{x}\right)
$$

Substitute equations (8) and (9) into equation (4):

$$
-\lambda_{t} \cdot C_{0} \cdot \exp \cdot\left(-\lambda_{t} \cdot \mathrm{t}\right)=\lambda_{x}^{2} \cdot D^{*} \cdot C_{0} \cdot \exp \cdot\left(-\lambda_{x} \cdot \mathrm{x}\right)
$$

Determine natural logarithm of concentration of saltwater as exponential functions of time and distance. Then combine the two equations:

$$
\begin{gathered}
-\lambda_{t} t=-\lambda_{x} x \\
\lambda_{t} t=\lambda_{x} \cdot \frac{x}{t} \\
\lambda t=\lambda x \cdot v
\end{gathered}
$$


Combining equations (10) and (11):

$$
\begin{gathered}
-\lambda_{x} \cdot v \cdot C_{0} \cdot \exp \cdot\left(-\lambda_{x} \cdot v \cdot \mathrm{t}\right)=D^{*} \cdot \lambda_{x}^{2} \cdot C_{0} \cdot \exp \cdot\left(-\lambda_{x} \cdot \mathrm{x}\right) \\
-v \cdot C_{0} \cdot \exp \cdot\left(-\lambda_{x} \cdot x\right)=D^{*} \cdot \lambda_{x}^{2} \cdot C_{0} \cdot \exp \cdot\left(-\lambda_{x} \cdot \mathrm{x}\right) \\
\lambda_{x}=-\frac{v}{D^{*}}
\end{gathered}
$$

Combine equations (5), (8) and (12):

$$
\begin{gathered}
J=-v \cdot C_{0} \cdot \exp \left(-\lambda_{t} \cdot \mathrm{t}\right) \\
J=-v \cdot C_{0} \cdot \exp \cdot\left(-\lambda_{x} \cdot v \cdot \mathrm{t}\right) \\
J=-v \cdot C_{0} \exp \left(-\lambda_{x} \cdot x\right) \\
J=-\frac{q}{\varnothing} \cdot C_{0} \exp \left(-\lambda_{x} \cdot x\right) \\
J=-\frac{K}{\varnothing} \cdot C_{0} \exp \left(-\frac{V}{D^{*}} \cdot x\right) \frac{d h}{d l}
\end{gathered}
$$

\section{METHODOLOGY}

The developed mathematical model in equation (13) was used to simulate saltwater movement in a medium with porosity of 0.42 and the hydraulic gradients vary from 1.875 to 30.000 between saltwater and freshwater. Parameters used in simulation were obtained empirically from previous work [16] and the initial concentration of saltwater at the interface was assumed to be $1.250 \mathrm{kgm}^{3}$. MATLAB software was used to simulate the mass flux of saltwater through the porous medium and the concentration of saltwater at various flow lengths was determined in equation (7).

The seepage velocities at different hydraulic gradients were obtained from the slope of the plot of mass flux against concentration of saltwater.

\section{RESULTS AND DISCUSSION}

In coastal aquifers, the geophysical parameters that change with the climatic conditions and human activities are hydraulic gradient and flow length while porosity is constant. The result of mass flux simulated from the mathematical model was presented in Table 1 and it showed that the mass flux decreases as the flow length increases. The results presented in Table 2 showed that the concentration of contaminant decreases as the hydraulic gradient increases. The value of mass flux $\mathbf{J}$ was plotted against the concentration $\mathrm{C}$ from Table 1 and Table 2 respectively for each hydraulic gradient.

The plot was found to be linearly related with slope of the line as the seepage velocity as shown in Figure 1 to Figure 5. The seepage velocities obtained from Figure 1 to Figure 5 showed that the seepage velocity of groundwater flow towards the sea increases with hydraulic gradient as presented in Table 3.

The seepage velocity of groundwater flow will reverse its direction when the fresh groundwater head in the coastal aquifers is less than sea level. 
The values of mass flux $\mathbf{J}$ were plotted against the flow length from Table 1 for each hydraulic gradient as shown in Figures 6 to 10 and the graphs of polynomial of degree two were obtained.

The equations of the graphs were used to determine the points at which the flow lengths of saltwater in the homogeneous aquifer when mass flux $\mathbf{J}$ are set to zero for different hydraulic gradients. This result showed that the flow length of saltwater decreases with increase in hydraulic gradient as presented in Table 3.

The point in the medium where the value of mass flux $\mathbf{J}$ is zero is the extent of diffusion of saltwater which is referred to as maximum flow length of diffusion for various hydraulic gradients.

A plot was prepared between the hydraulic gradients and the maximum flow lengths $\mathrm{x}(\mathrm{m})$. It was found to be related in polynomial of degree two for any porosity as shown in Figure 11 and the equation obtained from the graph is $i=675.5 x^{2}-514.5 x+95.03$ which can be used to predict the maximum flow length of contaminant in a medium of known hydraulic gradient and porosity. The maximum flow length $\mathrm{x}$ was found to decrease with increase in hydraulic gradient.

Table 1. Numerical modeled values of mass flux $\mathrm{J}$ of contaminant at various hydraulic gradients $\mathrm{i}$ with flow length $\mathrm{X}$ when the porosity of the medium is 0.420 .

\begin{tabular}{|l|l|l|l|l|l|}
\hline & $\mathrm{i}_{1}=1.875$ & $\mathrm{i}_{2}=3.750$ & $\mathrm{i}_{3}=7.500$ & $\mathrm{i}_{4}=15.00$ & $\mathrm{i}_{5}=30.00$ \\
\hline $\mathrm{X}(\mathrm{m})$ & $\mathrm{J}_{1}\left(\mathrm{kgm}^{-2} \mathrm{~s}^{-1}\right)$ & $\mathrm{J}_{2}\left(\mathrm{kgm}^{-2} \mathrm{~s}^{-1}\right)$ & $\mathrm{J}_{3}\left(\mathrm{kgm}^{-2} \mathrm{~s}^{-1}\right)$ & $\mathrm{J}_{4}\left(\mathrm{kgm}^{-2} \mathrm{~s}^{-1}\right)$ & $\mathrm{J}_{5}\left(\mathrm{kgm}^{-2} \mathrm{~s}^{-1}\right)$ \\
\hline 0.0 & 1.7634 & 3.5268 & 7.0536 & 14.1071 & 28.2143 \\
\hline 0.05 & 1.3939 & 2.2037 & 2.7540 & 2.1506 & 0.6557 \\
\hline 0.10 & 1.1019 & 1.3770 & 1.0753 & 0.3278 & 0.0152 \\
\hline 0.15 & 0.8710 & 0.8604 & 0.4198 & 0.0500 & 0.0004 \\
\hline 0.20 & 0.6885 & 0.5376 & 0.1639 & 0.0076 & 0.0000 \\
\hline 0.25 & 0.5442 & 0.3359 & 0.0640 & 0.0012 & 0.0000 \\
\hline 0.30 & 0.4302 & 0.2099 & 0.0250 & 0.0002 & 0.0000 \\
\hline 0.35 & 0.3401 & 0.1312 & 0.0098 & 0.0000 & 0.0000 \\
\hline 0.40 & 0.2688 & 0.0820 & 0.0050 & 0.0000 & 0.0000 \\
\hline 0.45 & 0.2125 & 0.0512 & 0.0015 & 0.0000 & 0.0000 \\
\hline 0.50 & 0.1680 & 0.0320 & 0.0006 & 0.0000 & 0.0000 \\
\hline
\end{tabular}

Table 2. Numerical modeled values of concentration $\mathrm{C}$ of contaminant at various hydraulic gradients $\mathrm{i}$ with flow length $\mathrm{X}$ when the porosity of the medium is 0.420 .

\begin{tabular}{|l|l|l|l|l|l|}
\hline & $\mathrm{i}_{1}=1.875$ & $\mathrm{i}_{2}=3.750$ & $\mathrm{i}_{3}=7.500$ & $\mathrm{i}_{4}=15.00$ & $\mathrm{i}_{5}=30.00$ \\
\hline $\mathrm{X}(\mathrm{m})$ & $\begin{array}{l}\mathrm{C}_{1}\left(\mathrm{kgm}^{-3}\right) \\
\times 10^{3}\end{array}$ & $\begin{array}{l}\mathrm{C}_{2}\left(\mathrm{kgm}^{-3}\right) \\
\times 10^{3}\end{array}$ & $\begin{array}{l}\mathrm{C}_{3}\left(\mathrm{kgm}^{-3}\right) \\
\times 10^{3}\end{array}$ & $\begin{array}{l}\mathrm{C}_{4}\left(\mathrm{kgm}^{-3}\right) \\
\times 10^{3}\end{array}$ & $\begin{array}{l}\mathrm{C}_{5}\left(\mathrm{kgm}^{-3}\right) \\
\times 10^{31}\end{array}$ \\
\hline 0.0 & 1.2500 & 1.2500 & 1.2500 & 1.2500 & 1.2500 \\
\hline 0.05 & 0.9881 & 0.7811 & 0.4881 & 0.1906 & 0.0290 \\
\hline 0.10 & 0.7811 & 0.4881 & 0.1906 & 0.0290 & 0.0070 \\
\hline 0.15 & 0.6174 & 0.3050 & 0.00744 & 0.0044 & 0.0000 \\
\hline 0.20 & 0.4881 & 0.1906 & 0.00290 & 0.0007 & 0.0000 \\
\hline 0.25 & 0.3858 & 0.1191 & 0.0113 & 0.0001 & 0.0000 \\
\hline 0.30 & 0.3050 & 0.0744 & 0.0044 & 0.0000 & 0.0000 \\
\hline 0.35 & 0.2411 & 0.0465 & 0.0017 & 0.0000 & 0.0000 \\
\hline 0.40 & 0.1906 & 0.0290 & 0.0007 & 0.0000 & 0.0000 \\
\hline 0.45 & 0.1506 & 0.0182 & 0.0003 & 0.0000 & 0.0000 \\
\hline 0.50 & 0.1191 & 0.0113 & 0.0001 & 0.0000 & 0.0000 \\
\hline
\end{tabular}




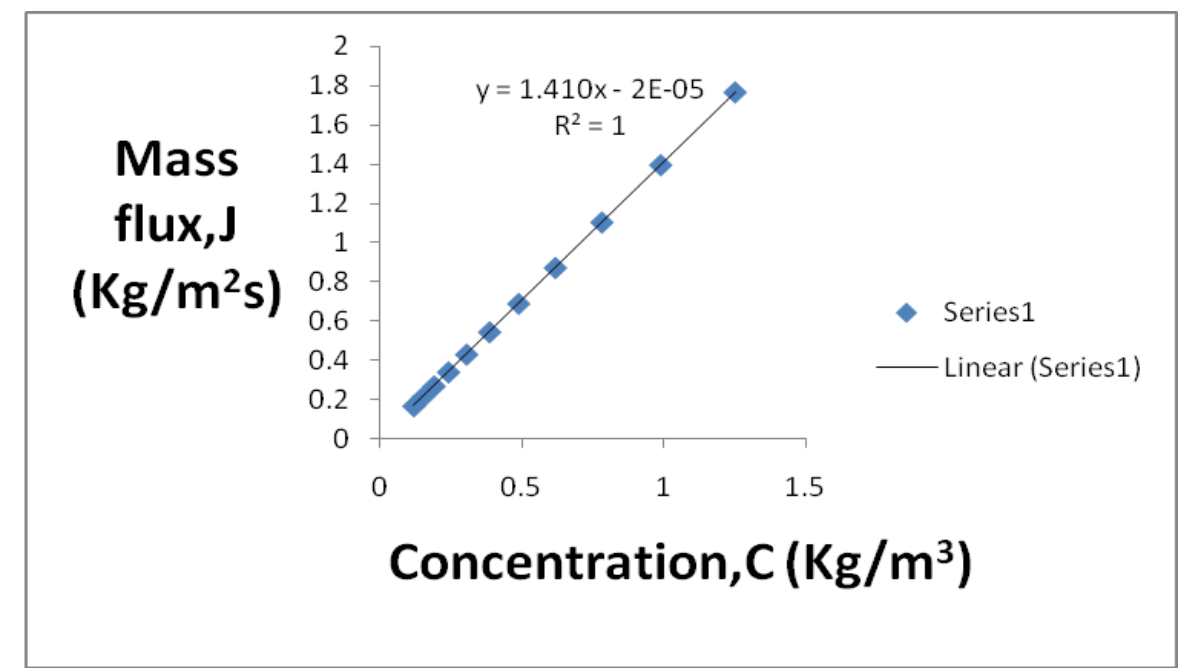

Fig. 1. Mass flux $\mathrm{J}$ against concentration $\mathrm{C}$ when porosity is 0.42 and $\mathrm{i}$ is 1.875 .

Table 3. Values of seepage velocity and maximum flow length (x) from the interface for various hydraulic gradients when the porosity of the medium is 0.42 .

\begin{tabular}{|l|l|l|l|l|l|}
\hline & $\mathrm{i}=1.875$ & $\mathrm{i}=3.75$ & $\mathrm{i}=7.50$ & $\mathrm{i}=15.0$ & $\mathrm{i}=30.0$ \\
\hline$v \times 10^{-4}\left(\mathrm{~ms}^{-1}\right)$ & 14.10 & 28.21 & 56.42 & 112.8 & 226.0 \\
\hline$x(\mathrm{~m})$ & 0.47 & 0.31 & 0.22 & 0.20 & 0.19 \\
\hline
\end{tabular}

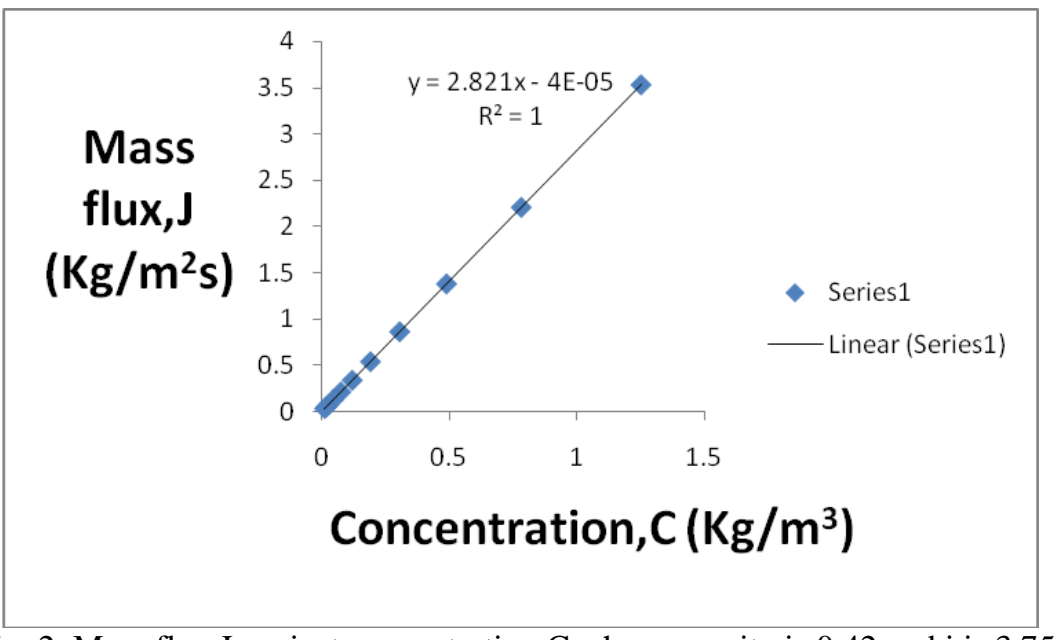

Fig. 2. Mass flux $\mathrm{J}$ against concentration $\mathrm{C}$ when porosity is 0.42 and $\mathrm{i}$ is 3.75 .

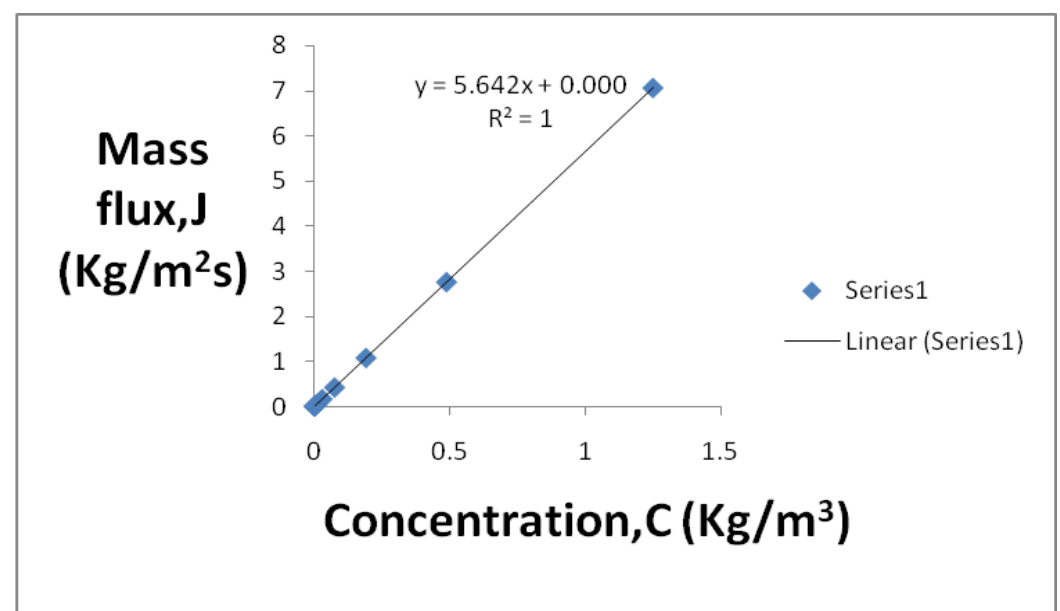

Fig. 3. Mass flux $\mathrm{J}$ against concentration $\mathrm{C}$ when porosity is 0.42 and $\mathrm{i}$ is 7.5 . 


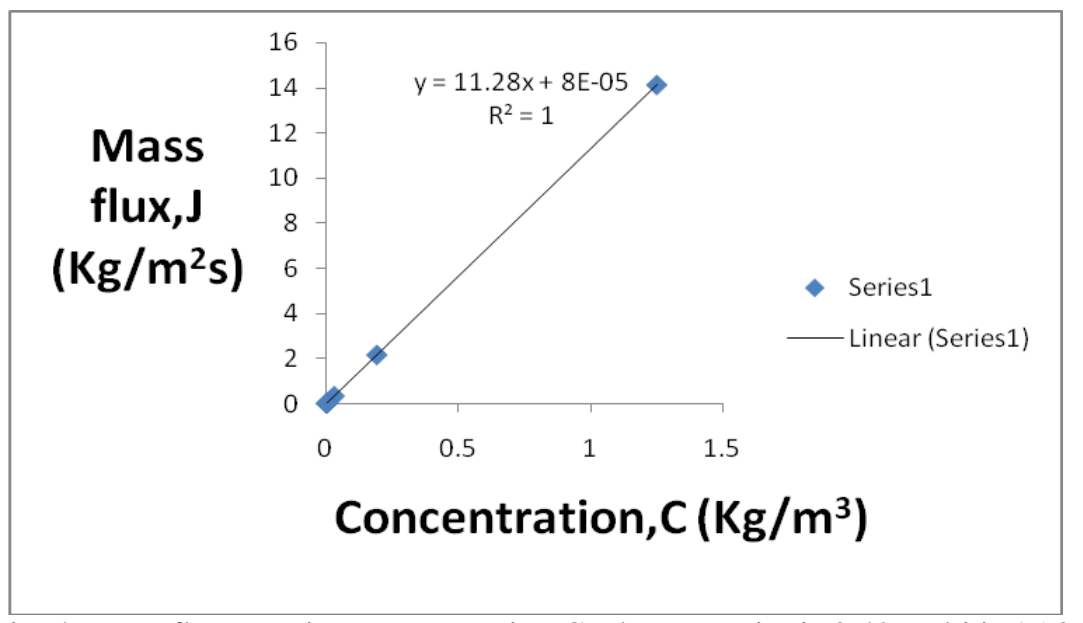

Fig. 4. Mass flux $\mathrm{J}$ against concentration $\mathrm{C}$ when porosity is 0.42 and $\mathrm{i}$ is 15.0 .

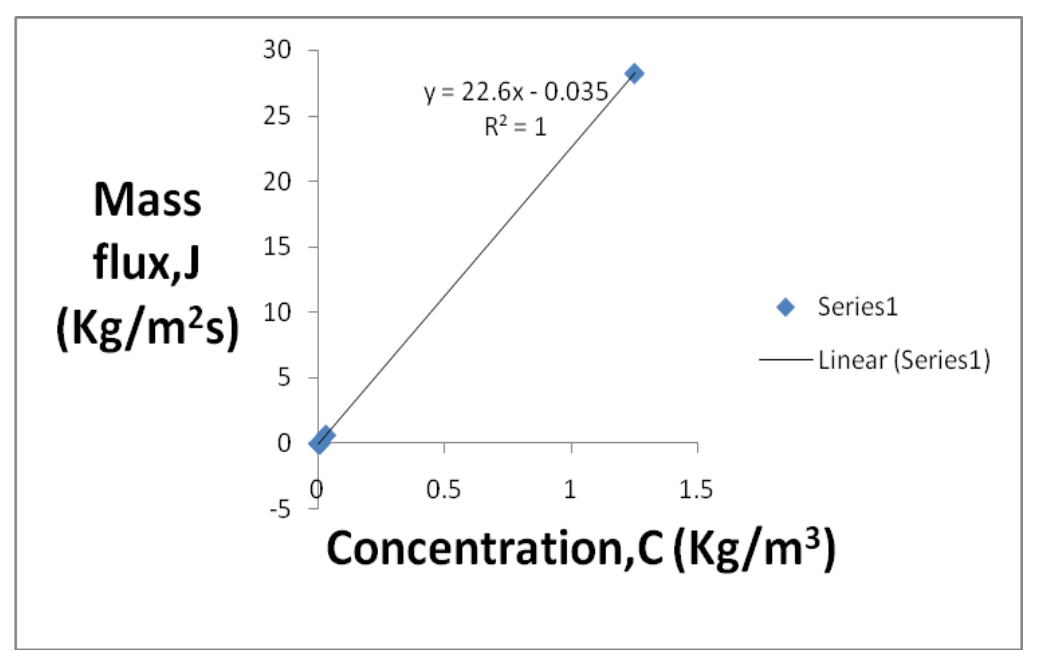

Fig. 5. Mass flux $\mathrm{J}$ against concentration $\mathrm{C}$ when porosity is 0.42 and $\mathrm{i}$ is 30.0 .

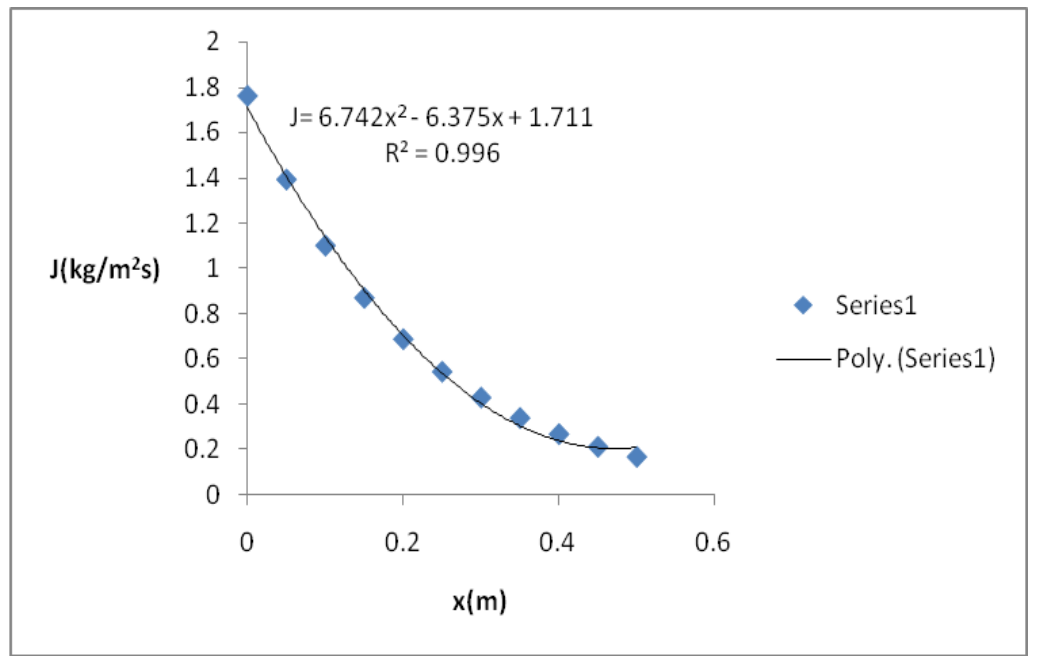

Fig. 6. Mass flux $\mathrm{J}$ against flow length $\mathrm{x}$ when porosity is 0.42 and $\mathrm{i}$ is 1.875 . 


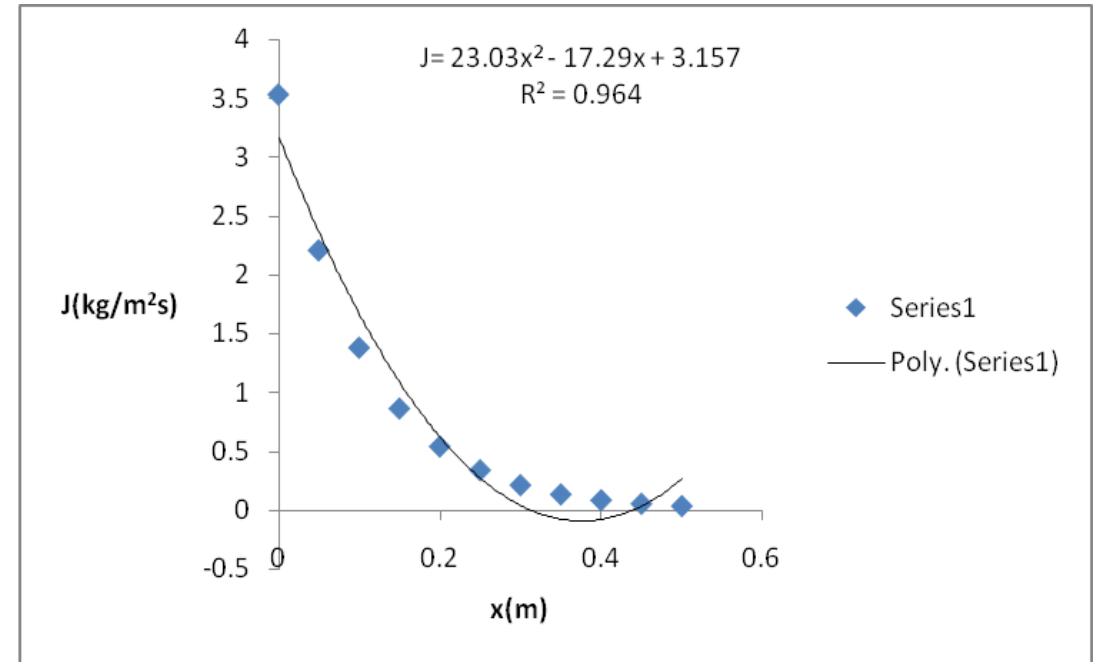

Fig. 7. Mass flux $\mathrm{J}$ against diffused length $\mathrm{x}$ when porosity is 0.42 and $\mathrm{i}$ is 3.75 .

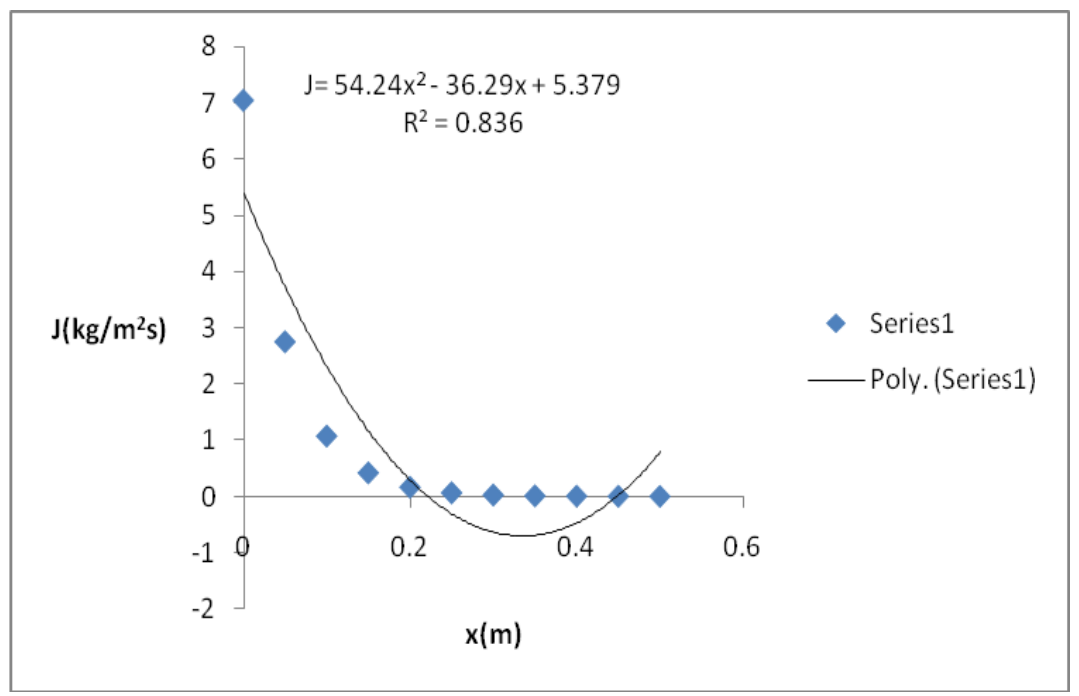

Fig. 8. Mass flux $\mathrm{J}$ against flow length $\mathrm{x}$ when porosity is 0.42 and $\mathrm{i}$ is 7.5 .

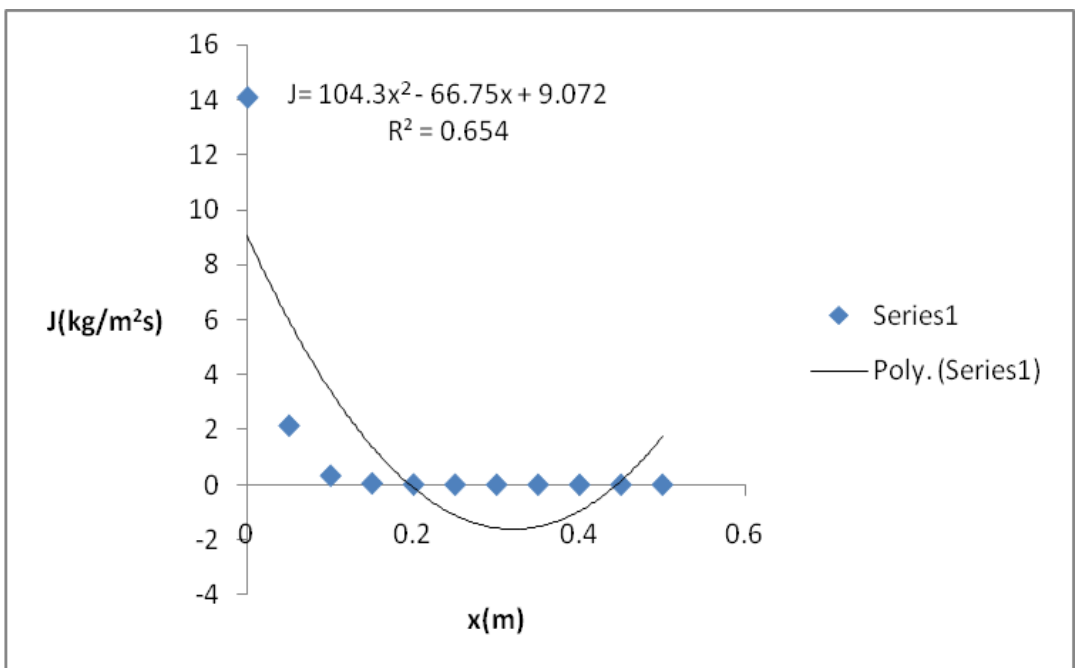

Fig. 9. Mass flux $\mathrm{J}$ against flow length $\mathrm{x}$ when porosity is 0.42 and $\mathrm{i}$ is 15.0 . 


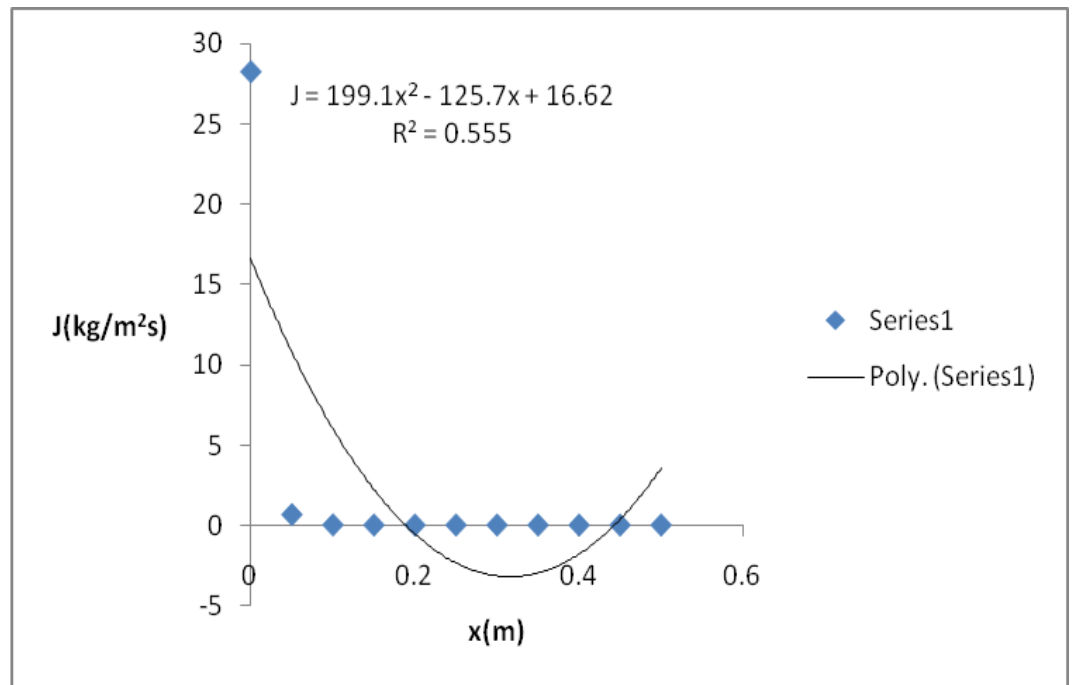

Fig. 10. Mass flux $\mathrm{J}$ against flow length $\mathrm{x}$ when porosity is 0.42 and $\mathrm{i}$ is 30.0 .

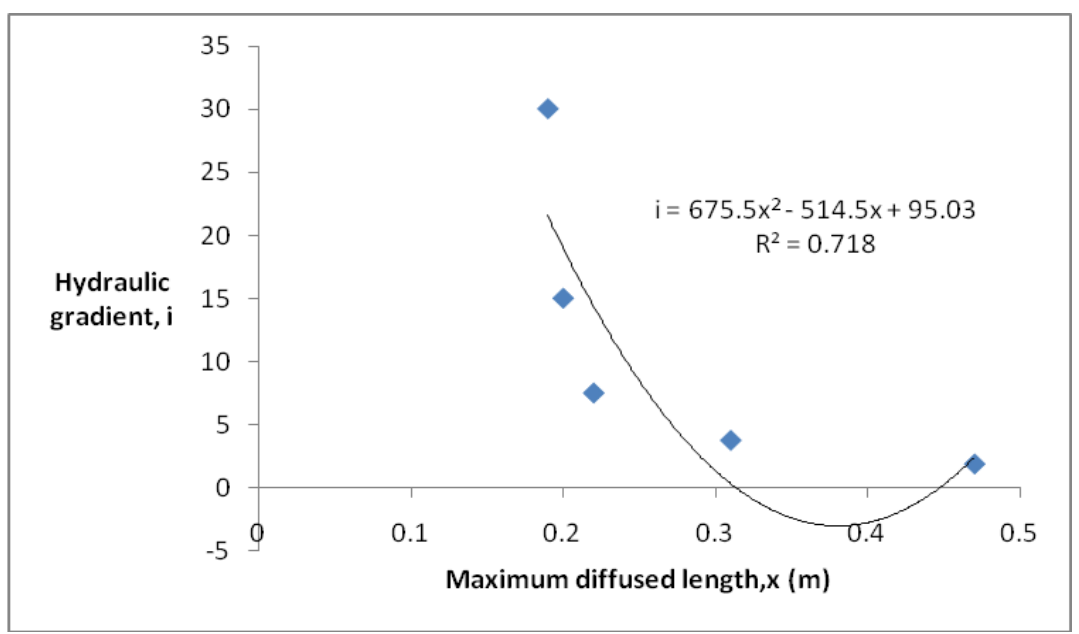

Fig. 11. Graph of hydraulic gradient $\mathrm{i}$ against maximum flow length, $\mathrm{x}$ when $\varnothing$ is 0.42 .

\section{CONCLUSION}

The hydraulic gradient of groundwater in coastal aquifer has influence on the flow of saltwater intrusion. When the hydraulic gradient is high the seepage velocity of fresh groundwater will be high and the flow length of saltwater towards inland will be reduced. The hydraulic gradient is a function of seepage velocity and flow length of saltwater. Increase in hydraulic gradient lead to increase in seepage velocity that resists the flow length of saltwater in coastal aquifer. Therefore, the hydraulic gradient of groundwater can control saltwater intrusion in coastal aquifer if the abstraction of freshwater is reduced.

\section{ACKNOWLEDGEMENTS}

The authors are grateful to Dr. Moses Awojobi and Dr. Abdulraheem Abdulrasaq of Kwara State University, Malete Kwara State, Nigeria for the constructive comments regarding the paper.

\section{REFERENCES}

[1] Wolfgang, K., Density flow in groundwater; Institute of Environmental Engineering, ETH Zurich, 2009. 
[2] Bear, J., Zhou, O., Bensabat, J., Three Dimensional simulation of seawater intrusion in heterogeneous aquifers with application to the coastal aquifer of Israel, First International Conference on Saltwater Intrusion and Coastal Aquifers- Monitoring, Modeling, and Management. Essaouira, Morocco, April 23-25, 2001.

[3] Bear, J., Arnold, V., Modelling groundwater flow and pollution. Reidel Publishing Company, 1990.

[4] McDonald, R.J., Russill, N.R.W., Miliorizos, M., Thomas, J.W., A geophysical investigation of saline intrusion and geological structure beneath areas of tidal coastal wetland at Langstone Harbour, Hampshire, N. S. (ed.) Groundwater Pollution, Aquifer Recharge and Vulnerability. Geological Society, London, Special Publications, vol. 130, 1998, p. 77-94.

[5] Adegoke, J.A., Popoola, O.I., Faluyi, O.O., Laboratory investigation of saltwater intrusion through porous media, Electronic Journal of Geotechnical Engineering, vol. 16, 2011, p. 1369 - 1381.

[6] Bhattacharya, A.K., Basak, S., Maity, P., Paira, L.K., Sankar, S., Maji, S.C., Hydrogeology of the bay of biengal Coast of India with special emphasis on saline water intrusion, Electronic Journal of Geotechnical Engineering, 2005.

[7] Freeze, R.A., Cherry, J.A., Groundwater, Prentice Hall, Inc., USA, 1979.

[8] Schwartz, F.W., Zhang, H., Fundamentals of groundwater, John Wiley \& Sons, New York, USA, 2003.

[9] Barlow, P.M., Ground water in fresh water-salt water environments of the Atlantic Coast, U.S. Geological Survey Circular 1262, 2003.

[10] Delleur, J.W., The handbook of groundwater engineering, CRC Press LL.C. 1999.

[11] Domenico, P.A., Schwartz, F.W., Physical and chemical hydrogeology; John Willey and Sons Inc. New York, USA, 1999.

[12] Olowofela, J.A., Adegoke, J.A., Determination of transition length in flow through porous sand material, Pacific Journal of Science and Technology, vol. 10, no. 2, 2005, p. 716-720.

[13] Nag, P.K., Heat and mass transfer, published by Tata McGraw-Hill, 2008.

[14] Pekdeger, A., Matthess, G., Schroter, J., Protection of groundwater against pathogenic bacteria and viruses. hydrogeology in the servica of Man, Memoires of the $18^{\text {th }}$ Congress of the International Association of Hydrogeologists, Cambridge, 1985.

[15] Floppen, J.W.A, van Herwerden, M., Schijven, J.F., Transport of escherichia coli in saturated porous media: dual mode deposition and intra-population heterogeneity, Water resources, vol. 41, no. 8, 2007, p. 1743-1753.

[16] Adegoke, J.A., Popoola, O.I., Faluyi, O.O., Analysis of physical parameters controlling saltwater intrusion in coastal aquifers, National Journal of Mathematical Physics Association, vol. 33, 2016. 